\title{
Markets, Tort LAW, AND REgulation TO ACHIEVE SAFETY Paul H. Rubin
}

Markets, tort law, and regulation are alternative methods of achieving safety. Of these, the market is the most powerful, but it is often ignored in policy discussions. I show that both for the United States over time and for the world as a whole, higher incomes are associated with lower accidental death rates, and I discuss some examples of markets creating safety. Markets may fail if there are third-party effects or if there are information problems. Classic tort law is a reasonable (although expensive) way to handle third-party effects for strangers, as in the case of auto accidents. In theory, regulation could solve information problems, but in practice many regulations overreach because of different information problems-consumers are unaware of unapproved alternatives. A particularly difficult information problem arises in the case of what I call "ambiguous goods"goods that reduce some risks but increase others (for example, medical care and malpractice.) Product liability focuses on these goods; over half of the litigation groups of the American Association for Justice are for ambiguous goods.

Increasing the price of these goods through tort liability may make consumers worse off because they are less likely to purchase more

Cato Journal, Vol. 31, No. 2 (Spring/Summer 2011). Copyright (C) Cato Institute. All rights reserved.

Paul H. Rubin is Professor of Economics at Emory University. This article was originally prepared for the Searle Civil Justice Institute Conference on "Litigation vs. Regulation: A Model of Economic Efficiency or Economic Headwind?" at George Mason University, November 18-19, 2010. The author thanks participants at that conference for helpful comments. He also thanks Margarita Zabelina, Eliska Repkova, and Griffin Edwards for research assistance, and Lee Mickus for information about electronic stability control systems. 


\section{Cato Journal}

expensive goods. At least in the case of drugs both the regulatory system and the tort system are probably overly restrictive, so using both is likely to lead to net consumer harm. This factor would argue for preemption-FDA approval should preempt state tort law.

\section{The Market for Safety}

There are three major forces for safety. We tend to think first of regulation and second of litigation in the form of tort law (including malpractice and product liability) to increase safety, but in fact the most important force for safety is the market itself. People demand safety and markets provide what people want. Moreover, safety is what economists call a "normal" good-a good where demand increases with income. Therefore, as societies become richer through market exchange and economic freedom, safety increases. The other two forces for safety may also lead to increases (although this is by no means certain), but the role of markets is paramount.

In this article, I discuss the three major forces for safety. In discussing regulation and tort law, I will compare each to the market. I then discuss interactions between regulation and tort law. Throughout the discussion, I stress the role of ambiguous goodsgoods that both increase and decrease safety. For example, pharmaceuticals reduce risk of disease but have side effects that are sometimes harmful. This class of goods turns out to be both important and difficult for any of the three safety systems to handle.

Markets will provide the amount of first-party safety that consumers desire if the information environment is correct. That is, if consumers want safer products enough to be willing to pay for them, then businesses will find providing safety profitable and will provide the level of safety that consumers desire. This is the strongest force for safety.

As shown in Figures 1 and 2 and in Table 1, as incomes increase, accidental death rates, a measure of safety, are reduced. In Table 1 we see that coefficients on death rates as a function of per capita incomes are negative, meaning that higher incomes lead to lower death rates, and these coefficients are statistically significant. This happens both within the United States over time (Figure 1) and across countries (Figure 2). The results of the time series and crosssectional regressions of accidental death rates on per capita GDP are the following. In case of the U.S. time series data, the coefficient on per capita GDP is -0.0009 with a t-statistic of -10.4621 . The $\mathrm{R}^{2}$ 
FIGURE 1

U.S. ACcidental Death Rates and Per Capita GDP, 1959-2004

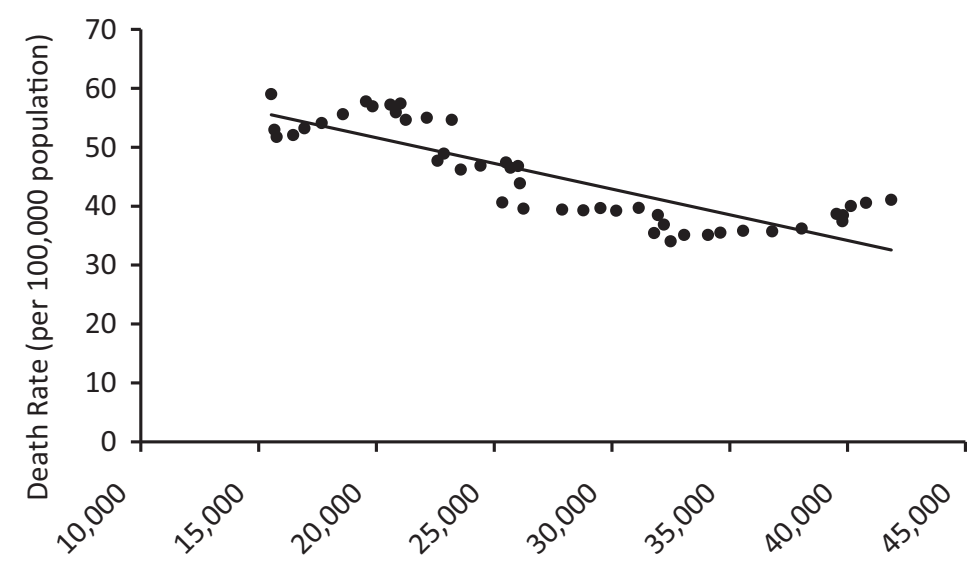

Per Capita GDP (in 2005 chained US\$)

SourCES: Bureau of Economic Analysis (2010:10), National Bureau of Economic Research (2009:4), and U.S. Census Bureau (2009:12).

value for this regression is 0.7133 . In the case of the time series data for 112 countries, the coefficient on per capita GDP is -0.0005 with a t-statistic of -2.6579 . The $R^{2}$ value for this regression is 0.0603 . Table 1 displays the simple regression results.

The U.S. time series data were collected for the period 1959 to 2004 while the cross-sectional international data were collected for 2002. The accidental death rate (dependent variable) is defined as the number of accidental deaths per 100,000 population. The cause of death was determined according to the International Statistical Classification of Diseases (Revisions 7, 8, 9, and 10) and includes all unintentional deaths. In the case of the United States a separate chart for motor vehicle accidents is included. ${ }^{1}$

${ }^{1}$ Due to frequent revisions of the International Statstical Classification of Diseases codes and the accidental death data being condensed or expanded into different groups in each revision, it is possible that the reported accidental death data may be slightly inconsistent over time. However, the death counts when graphed show a clear trend without any large deviations. Thus the impact of changes in the ICD codes is only minor. 
Cato Journal

FIGURE 2

International ACCidental Death Rates AND PER CAPITA GDP, 2002

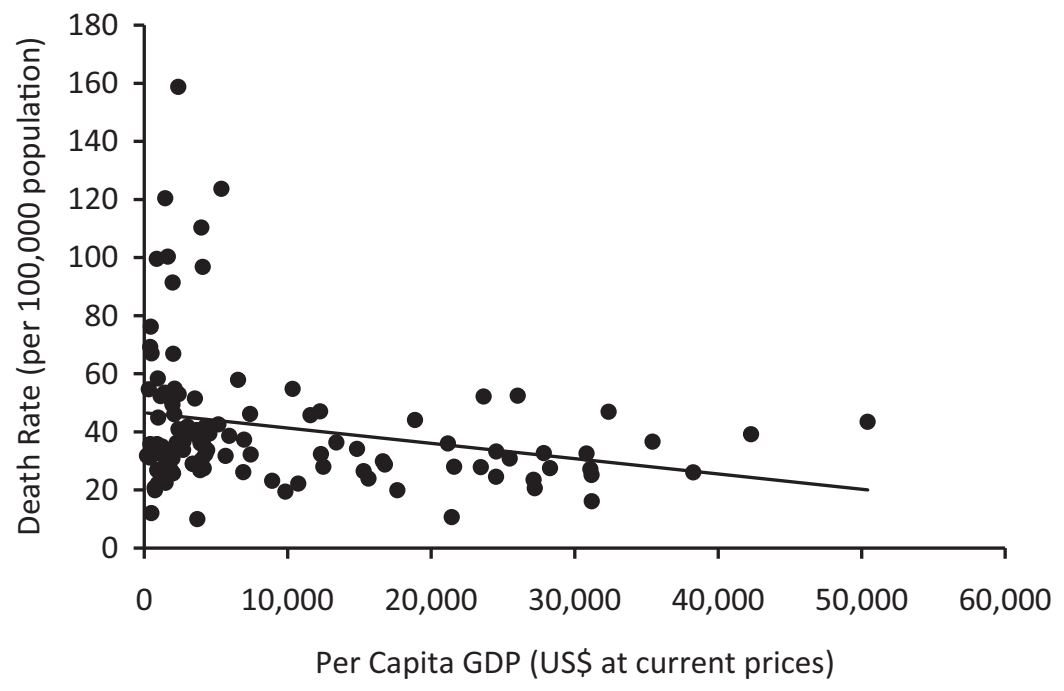

Sources: United Nations Statistics Division (2009:11) and World Health Organization (2004:12).

TABLE 1

Time Series and Cross-Sectional Regression Results, accidental Death Rate as a Dependent Variable

\begin{tabular}{lcccr}
\hline & \multicolumn{2}{c}{ Time Series } & \multicolumn{2}{c}{ Cross Sectional } \\
& Coefficient & t value & Coefficient & t value \\
\hline Constant & 69.0457 & 29.0382 & 46.5773 & 16.1009 \\
Per Capita GDP & -0.0009 & -10.4621 & -0.0005 & -2.6579 \\
Observations & 46 & & 112 & \\
R-squared & 0.7133 & & 0.0603 & \\
& & & & \\
\hline
\end{tabular}

SourcEs: Bureau of Economic Analysis (2010:10), National Bureau of Economic Research (2009:4), and U.S. Census Bureau (2009:12). 
TABLE 2

DesCRIPTIVE Statistics

\begin{tabular}{lccc}
\hline & Mean & Min. & Max. \\
\hline U.S. GDP per capita & $27,466.5$ & $15,534.5$ & $41,849.4$ \\
U.S. Accidental Death Rate & 45.1 & 34.03 & 59.02 \\
$\begin{array}{l}\text { Cross Sectional GDP } \\
\text { per capita }\end{array}$ & $9,479.14$ & 193.5 & $5,0417.2$ \\
$\begin{array}{l}\text { Cross Sectional Accidental } \\
\text { Death Rate }\end{array}$ & 41.59 & 9.98 & 158.75 \\
\end{tabular}

SOURCES: Bureau of Economic Analysis (2010:10), National Bureau of Economic Research (2009:4), and U.S. Census Bureau (2009:12).

The values of U.S. per capita GDP are in 2005 chained U.S. dollars. The values of per capita GDP for countries in the crosssectional analysis are in current U.S. dollars. Table 2 displays the mean, minimum, and maximum values for the variables. While there are many other factors involved, the simple graphs and regression equations capture an important component of what is going on-higher incomes lead to more safety. ${ }^{2}$ Moreover, the result is economically as well as statistically significant: going from 1959 to 2004, the model actually overpredicts the fall in death rates. The actual death rate in 2004 is 41 per 100,000 population, but the model predicts a death rate of 33 per 100,000 based solely on the increase in incomes over this period. This means that the relationship is important as well as statistically significant.

There is much additional evidence for the role of markets. There is a very substantial empirical literature estimating "value of life" based on wage premiums demanded by workers to accept additional risks. The basic notion in this literature is that markets respond to worker preferences for safety. If markets did not respond, these studies would not be possible because the wage premiums would not exist. Viscusi and Aldy (2003) estimated an income elasticity of value of life of about 0.5 . Thus, a 1 percent increase in income would lead to a 0.5 percent increase in the value of life. Since markets respond

${ }^{2} \mathrm{~A}$ complete analysis would need to consider many other factors such as age and occupational distributions and regulation. Nonetheless, the regression makes the point that income and safety are positively related. 


\section{Cato Journal}

to consumer valuation of safety, this implies a significant market response to income. Safety agencies routinely use data from these models in mandating safety improvements.

Product safety is also improved by voluntary standards organizations, such as the International Organization for Standardization or the American National Standards Institute. These are organizations largely funded privately by firms in the relevant businesses who find increasing the safety of their products profitable. For an example of market provided safety, consider ground fault circuit interrupters (GFCIs), the little boxes associated with electric plugs in most bathrooms and elsewhere that prevent electrocution. These were developed privately and widely adopted before they were mandated by law (see Peck and Sage 2003). Moreover, the process of adoption took many years, with the National Electric Code (a voluntary set of standards) commonly adopted as law by the states. During this time the technology continually improved due to private efforts. This is an example of a market increasing safety in subtle and nonobvious ways. Examination of voluntary codes for almost any product would find similar safety improvements. Much of the work of the Consumer Protection Safety Commission (CPSC), for example, consists of working with voluntary standards organizations.

For another example, consider electronic stability control systems, the name for rollover protection technology for automobiles. These were first implemented by Mercedes and other manufacturers in 1996, and the number of vehicles with such complex systems has increased continually since then (Durisek and Granat 2008). The National Highway Traffic Safety Administration (2007) did not formally address this issue until 2001 and did not pass a rule until 2007. Moreover, NHTSA's involvement was possible only because the industry had voluntarily done the research needed to develop these complex systems.

Because markets do lead to increased safety and because wellfunctioning markets will provide the correct amount of safety (as measured by consumer preferences), in what follows I will compare regulation and tort law with the market solution. I will show that these alternatives can sometimes improve on the market solution, but that they can also make the situation worse.

There are two qualifications to the above statement regarding the efficiency of the market. First is the limit to first-party safety and second is the state of the information environment. Moreover, some 
products are both safe and unsafe. That is, some products can lead to reductions in some risks but increases in other risks. These products create difficulties for the market and for both the regulatory and the tort system, mainly because of difficult information problems associated with this class of products.

There is another point to make about markets and safety. Markets provide the amount of safety consumers desire but they mostly do so quietly. Products become safer over time as minor improvements occur, but these may not be noticed by consumers, as discussed earlier for GFCIs. Litigation and regulation are more obvious than pressure from markets, but as I show, they are not necessarily better.

Indeed, markets are most noticeable when they fail-when there is some mishap. It is at this point that there is pressure to "Do something"- either stronger regulation or a lawsuit to punish the evildoers, or both. For example, the predecessor of the Food and Drug Administration was empowered to demand premarket approval of drugs as a result of poisoning by elixir sulfanilamide in 1937. In 1962 the FDA was allowed to demand proof of efficacy as well as safety in drugs as a result of the harms caused by thalidomide, even though the FDA already had enough power to prevent the sale of this drug in the United States. At the CPSC we referred to "headline hazards," meaning that regulatory efforts were commonly spurred by notorious accidents, even if the products involved were relatively harmless. Recently the CPSC Improvement Act, passed in response to lead found in some toys, has greatly expanded the power of the agency and has probably caused the shutdown of the used children's products industry (Trottman 2008, Rubin 2009). ${ }^{3}$

\section{First- and Third-Party Safety}

In deciding on the level of safety associated with a product, consumers will consider risks to themselves (first-party safety). However, some products may impose risks on third parties who are not part of the transaction. In these cases, consumers will purchase too little safety. ${ }^{4}$ In modern societies, the most important such product is the automobile. Automobiles can impose risks to the driver and to passengers (first-party risks). Presumably purchasers of cars will

${ }^{3}$ For a similar argument with respect to regulation in response to financial breakdowns, see Ribstein (2003).

${ }^{4}$ I consider only physical safety of consumers and only the United States. 


\section{Cato Journal}

consider these risks when deciding on the level of safety to acquire when buying a car. Features such as seat belts, collapsible steering columns, and air bags impact this form of safety. However, automobiles can impose risks on third parties as well. These may be to other drivers (from collisions) or to pedestrians or bicyclists or motorcyclists. Drivers have some incentive to consider collision risks since they may be harmed as well, but these incentives are inadequate because car buyers will not fully consider risks to other cars and drivers. Drivers will have little reason to consider risks to pedestrians or to cyclists. Thus, in buying a car a consumer will purchase too little safety equipment. Fires may also cause harms to third parties, particularly in multifamily dwellings. Again, because consumers bear part of the risk of fires, they will make some effort to reduce that risk. But because they bear only part of the risk, consumers will spend too little to reduce the risk of fires. It might be possible for tort law or regulation to efficiently improve safety when there are third-party effects.

\section{Information Asymmetries}

Lack of information may also impede the functioning of markets. Most remaining risks in modern society are rather small because markets have already acted to reduce large risks. It may not pay for a consumer to learn about these risks because the cost of the time spent in such learning may outweigh the expected benefits of the additional safety. Nonetheless, there are many relatively low-cost sources of information for widely distributed products, such as cars or drugs (see Polinsky and Shavell 2010). Media will inform consumers of risks. Competitors making less risky products also have incentives to advertise this. There are sources of information such as Consumer Reports and other magazines and media, including the nightly news. Consumers can discuss risks and mishaps with each other, and the Internet-with its product rating sites, social groups, and blogs-has given this mechanism great power. The media often publicize these risks and firms suffer losses in stock value when products are identified either by tort suits or by regulatory agencies as causing harms (Rubin, Jarrell, and Murphy 1988; Rubin and Prince 2002).

Moreover, there are market corrections for lack of safety information. A firm with a safer variant has an incentive to advertise this, and in so doing to inform consumers (directly or indirectly) about risks from other products. For example, Volvo ads point out the 
risks of automobile accidents by claiming that Volvo is less likely to suffer such accidents. Likewise, cigarette companies making lowtar cigarettes emphasized the risks of smoking by claiming that they were safer, before they were stopped by misguided regulation (Calfee 1997). Nonetheless, for low-probability events or events where causation is delayed or uncertain, information may be difficult to obtain and understand, and markets may not work well. Again, there might be possibilities for improvement in this case.

\section{Ambiguous Products}

Certain products and services reduce some risks but increase others. The prime examples of these ambiguous products are drugs and medical care. The primary function of these products is to reduce risks, but they may in turn create different risks. For medical care, the additional risks are called "malpractice." For drugs they are called "side effects." Proper regulation of the risks associated with these items requires a careful balance between harms created and harms averted. It is not clear that any of the three systems under consideration can correctly provide this balance. Markets may not work because the risks are often subtle and hidden, and so information problems may arise. For example, sick people see physicians and take drugs. Even so, they may become sicker or perhaps die. If they suffer harms, they may not be able to tell if these harms are due to the underlying illness or to behavior of the physician or drug. Therefore, information about competence of a physician or safety of a drug may be difficult for an individual to determine.

\section{The Market: Summary}

In sum, markets provide a good deal of safety. Much of this is not noticed by consumers as it is done quietly and as a routine part of normal business operations. But for risks where third parties are involved or for risks where information may be lacking, other forces—regulation or tort law_may be desirable. Where products and services both reduce and increase risks, more difficult issues arise.

\section{Regulation}

There are many agencies that regulate consumer safety: the National Highway Traffic Safety Administration for automobile and 


\section{CAto Journal}

traffic safety, the Food and Drug Administration for safety of foods and drugs, the Federal Aviation Administration for airline safety, and the Consumer Product Safety Commission for consumer product safety. ${ }^{5}$ Regulation mostly works ex ante: regulators mandate safety before products are manufactured or sold, although agencies also generally have recall authority as well.

From the preceding analysis, some principles are immediately obvious. Where markets will work then there is no need for regulation. Markets work when risks are to first parties and potential victims are informed about risks or can easily learn about risks. If risks affect many users of a consumer product, then there will be forces leading to safety. I discuss first information, and then third-party effects.

\section{Information}

If consumers are misinformed about risks and underestimate risks, there is an argument for regulation because consumers may unknowingly purchase risky products. ${ }^{6}$ A simple solution to information problems is to provide the missing information. In cases where risks are easily explained and remedies simple, information provision, for example, through labeling, would be a feasible alternative. This would apply to many aspects of auto safety regulation, such as seatbelts and airbags. It would also apply to pharmaceuticals. For example, the Food and Drug Administration could require manufacturers to prominently indicate that some drug "Has not been approved by the FDA" and allow consumers to take their chances if they so desire. But agencies do not like that approach and avoid it unless it is forced on them, as in the case of cigarettes and dietary supplements.

However, information provision will not always be the best solution. Information may be complex or difficult to absorb. Moreover, for some risks, a regulator may believe (correctly or incorrectly) that a consumer if properly informed would not ever buy the product, so that a ban is appropriate. This is presumably the justification for

${ }^{5}$ I confine my discussion to federal agencies and I omit discussion of OSHA and other agencies that deal with workplace safety. I was chief economist at the CPSC from 1985-87. Since all dangerous products have their own agency, it is sometimes said that the CPSC is responsible for safety regulation of all safe products. ${ }^{6}$ In many cases consumers may overestimate risks. This may lead to inefficient decisions, as consumers may not purchase the optimal product mix. There are few corrective forces for this misinformation. Think of an airline ad: "Even though planes sometimes crash, overall flying is still 100 times safer than driving." 
forbidding the sale of unapproved pharmaceuticals and toys with small parts or high levels of lead. However, this creates a danger of overreaching. Regulators may not understand what risks consumers might be willing to take, or what tradeoffs consumers might find worthwhile. For example, it is my understanding that many consumers suffering from arthritis would have been willing to continue using Vioxx, even given the apparent risk of heart attacks.

It is clear that regulators would like to ban the sale of cigarettes, but they do not have the power because voters who smoke would punish elected representatives if this were allowed. Regulators have instead required extensive warnings and limits on sale. Similarly, when the FDA attempted to regulate dietary supplements, consumers protested to Congress, which stopped the agency. However, when the CPSC mandated that baby cribs have slats no more than $23 / 8$ inches apart to avoid infant strangulation, consumers were pleased that children were protected from this risk, which was probably unknown to them before the CPSC action. Manufacturers were also pleased as this rule ended the used crib market.

Arguments based on lack of information may lead to overregulation. There is a risk of overregulation in many markets, most fully demonstrated in the case of the FDA regulation of drugs (first analyzed by Peltzman 1973). This overregulation is especially likely in the class of ambiguous goods because there is an asymmetry with respect to some risks. If a regulator allows an unsafe product (a Type 1 error) and consumers are injured, then Congress and the press will generally blame the regulator. If the regulator does not allow a safe product (a Type 2 error) and consumers are harmed by the lack of this product, the injured parties will often not know that they could have been saved by a product. Consequently, the FDA is excessively cautious and consumers are harmed. ${ }^{7}$ This excess caution applies both to approval of a drug for sale and to promotion of that drug once it is approved. It is interesting that the FDA prides itself on being a scientific organization and rejects anecdotal information about the benefits of drugs, but in discussing its drug regulation

\footnotetext{
${ }^{7} \mathrm{~A}$ good source of information about FDA overcaution is the FDA Review website organized by Daniel Klein of George Mason University (www.fdareview .org/index.shtml). Klein shows that all 35 economists, including two Nobel Prize laureates, identified as being experts on some aspect of the FDA believe that it is too restrictive. This website also has many citations to the literature showing that the FDA imposes net harms on consumers.
} 


\section{Cato Journal}

program it relies on anecdotes rather than scientific evidence about the effects of its regulation. For example, Meadows (2006), in an official history of the FDA, provides many examples of FDA regulation but cites no evidence of the costs or net benefits of regulation.

Rather than focus on past failures of the FDA, critics should publicize current issues. Every year PhARMA (the pharmaceutical industry trade association) puts out a publication listing drugs in trial. An interested private organization could take information about promising drugs, perhaps for currently untreatable conditions, and publicize those drugs. The drug companies could not put this information out because they are afraid of antagonizing the FDA, but a private party could. The example of AIDS has shown that if a group of patients becomes organized, they are able to force the FDA to act more quickly.

\section{Third-Party Effects}

Although regulators seem to somewhat understand issues of information failure, there seems to be little understanding of third-party effects. That is, many regulations affect purchasers of products where there is little information justification and no justification based on third-party effects. Consider, for example, regulation of automobile safety. Certain features of an automobile affect only drivers or purchasers. These concern what is commonly are referred to as the "second collision" or "second impact"-the collision between the occupant of the automobile and the automobile itself following the "first collision" between the vehicle and another object. Remedies for this second impact include lap and shoulder belts, padding, airbags, and collapsible steering columns. Note that none of these items have any influence on third parties. In fact, by making occupants safer they may actually increase risks to third parties because of so-called Peltzman effects-that is, the tendency of drivers in safer vehicles to compensate by driving more carelessly (Peltzman 1975). Other elements of auto safety do affect third parties. These include brakes, lights, mirrors, dangerous hood ornaments, and bumper heights. In regulating auto safety NHTSA does not seem to distinguish between regulations that involve only first parties and those that involve third parties as well.

Other agencies ignore this distinction as well. For the FDA, some drugs-primarily antibiotics and vaccines - have third-party effects. For antibiotics, the third-party effects are ambiguous. Antibiotics 
may reduce the spread of infectious diseases. However, overuse may lead to antibiotic resistance which also harms third parties. Vaccines seem to provide unambiguously beneficial third-party effects. For antibiotics, the agency actually seems to make approval more difficult in spite of these third-party effects (Rubin 2005). But most drugs do not have such effects; most involve only the patient. Nonetheless, the agency does not hesitate to regulate these drugs. Similarly, some products regulated by CPSC-primarily those associated with fires - may have third-party effects, but most (for example, toys) do not and again this does not impact agency decisionmaking. ${ }^{8}$

\section{Regulation: Summary}

In sum, regulators seem to pay insufficient attention to market forces. While some regulation is justifiable because of lack of consumer information, much is not. Even when provision of information would be a reasonable remedy, the agencies will often directly regulate. Moreover, lack of information about alternatives can lead to harmful regulation in the case of ambiguous goods. Regulators appear to ignore the distinction between first-party and third-party effects.

\section{Tort Law}

Classic tort law dealt with accidents between "strangers"-parties with no pre-accident relationship. ${ }^{9}$ This is a strict third-party effect. Because the parties had no pre-accident relationship, they could not decide in advance what terms would govern in the event of an accident, nor could they bargain over optimal safety precautions. Therefore, the courts were forced to decide how to allocate costs and liability if there was a mishap. This model still governs the most common class of tort events—automobile accidents. Here the tort system (coupled with traffic laws and private insurance) works reasonably

${ }^{8}$ When I worked at the CPSC I never heard the issue of third-party effects mentioned. To regulate only items with such effects would have led to a virtual shutdown of the agency.

${ }^{9}$ Some believe that tort law has a compensation function in addition to its deterrence function. However, because administrative costs of the tort system are so high (on the order of 50 percent or more) economists believe that other methods such as direct first-party insurance or government insurance are more efficient and that the tort system should not be relied upon for compensation. 


\section{CAto Journal}

well, although there are those who suggest that "no-fault" accident insurance would be an improvement because it would save substantial amounts in legal fees (Keeton and O'Connell 1965).

The tort system contributes to safety through an ex post mechanism. Those causing injuries are required to pay the victims, and the threat of this payment causes potential injurers to take precautions to avoid accidents. Under certain circumstances it can be shown that this system will lead both victims and injurers to take optimal (efficient) precautions for accident avoidance (Landes and Posner 1987, Shavell 1987). ${ }^{10}$

However, modern tort law has expanded well beyond this model. The most difficult areas of tort law are product liability and medical malpractice. Both of these differ significantly from classic tort law. In particular, in both cases parties are not strangers; they are in a preaccident relationship as sellers and buyers or as doctors and patients. This has three implications. First, parties could in principle agree through contract or through a system of waivers on the level of precautions before any accident occurred. Then if the injurer did not adhere to this agreement, there could be a suit for breach of contract. Second, they could also agree in advance on the terms that would govern in the event of an accident. If so, they would likely agree on smaller damage payments than those provided by the tort system (Rubin 1993). Third, any payments by injurers will ultimately be reflected in the price of the good, and so will be paid for by customers. Thus, the tort system will act as an insurance system: consumers pay premiums in the form of higher prices for goods and services, and receive compensation if they are injured. To the extent that tort law is mandatory-so consumers cannot choose to opt out of tort law - then the insurance is mandatory. If tort law mandates insurance that is not worth the cost to consumers, then consumers may choose not to purchase products with the attached insurance even if the product would otherwise be desirable.

There are many problems with the product liability and malpractice systems as methods of accident prevention. Polinsky and Shavell (2010) provide a comprehensive critical analysis of product liability. Their critique focuses on several issues. First, for widely sold products, there are market and regulatory forces that will lead to safety,

${ }^{10}$ Optimal precautions are not maximal precautions. In other words, the optimal number of accidents is greater than zero. 
so the product liability system is at best marginal in adding safety. Second, the system is extremely expensive-about 50 percent of the cost of the system is for expenses, including legal fees. These administrative costs are much greater than either private insurance or regulatory costs, which is why the tort system is not an efficient system for compensation of victims. Third, the system may not even work on its own terms. That is, it may not even increase safety.

Tort litigation focuses disproportionately on ambiguous goods. The American Association for Justice (formerly the Association of Trial Lawyers of America) lists 105 litigation groups (groups of affiliated attorneys specializing in one type of lawsuit) on its website (www.justice.org/cps/rde/xchg/justice/hs.xsl/1150.htm). Of these, over half (55) specialize in litigation involving ambiguous goods. Lawyers focus on ambiguous goods for several reasons. First, people using these goods are already in some danger. Something unfortunate such as death is more likely to occur when someone is already sick or injured. Moreover, since the person was already in a bad situation, it is not always possible to determine if the good or service was responsible for the harm suffered. Some lawyers specialize in casting blame on physicians or drugs in this situation. Finally, injurers in these situations (doctors, pharmaceutical companies) are wealthy or have insurance (are "deep pockets") and so make inviting targets.

To the extent that litigation increases the price of such goods, then one effect is to reduce the quantity demanded of the good and so perhaps increase risk. The result is that some consumers may not purchase these goods and so may forgo the safety benefits of the goods. Consumers may choose not to purchase goods because goods are bundled with insurance and some of the insurance-notably, that for "pain and suffering" (also called nonpecuniary damages) — is not worth the cost, and consumers never voluntarily buy such insurance. ${ }^{11}$ Moreover, because of high administrative costs of the tort system, the value even of what would otherwise be desired insurance may not be worth the cost. In fact there is evidence that reducing the scope and power of tort law leads to increased safety. Rubin and Shepherd (2007) show that from 1981 to 2000 tort reforms in the

\footnotetext{
${ }^{11}$ Insurance companies generally do not offer such insurance, presumably because they know that consumers would not buy it. If consumers do not want such insurance when the overhead costs of the insurance are low, then they perforce would not want it through the tort system, where overhead costs are much higher.
} 


\section{CAto Journal}

states led to 24,000 fewer accidental deaths because of increased access to emergency medical care. Cutting back the scope of tort law (for example, by capping damage payments) actually led to a decrease in accidental deaths. Thus, on the margin, tort law led to reduced, not increased, safety.

\section{Tort Law: Summary}

In sum, classic tort law dealing with accidents between legal strangers (mainly auto accidents) is a reasonable way to reduce risks from driving. However, expansions of tort law into non-stranger areas (primarily malpractice and product liability) have severe problems. Tort law is the most expensive method of providing safety because of high transactions and administrative costs, including legal fees. Moreover, it is not clear that this branch of law does actually increase safety on the margin. Because tort law makes safety-increasing products (for example, drugs and medical care) more expensive, it may actually increase risks. Empirical evidence is consistent with this proposition.

\section{Interaction between Tort Law and Regulation}

Many products are governed both by ex ante regulation and by ex post liability for tort law. Whether this is a desirable set of policies is highly debated. The issue is called "preemption" and the question is whether FDA or other federal government safety regulation preempts state tort law. The issue has been most carefully studied for drug regulation by the FDA. ${ }^{12}$

The situation is this: Because of fear of negative publicity if a harmful drug is approved, the FDA is overly cautious in approving drugs. That is, patients are harmed and even killed because some beneficial drugs are not approved or approved too late, or because FDA advertising regulations mean that some patients or physicians do not learn about beneficial drugs. Patients are also harmed by tort regulation, which increases the price of ambiguous goods (including drugs) and so prices some consumers out of the market, even though on net the drug is beneficial (since FDA overcaution means that

\footnotetext{
${ }^{12}$ This section is based on Calfee et al. (2008). That brief has many additional literature citations. I was a co-author of that brief, but received no compensation, as stated in the brief.
} 
many useful drugs will be delayed or not approved at all and any drug which is approved has a very high probability of being beneficial.)

This issue has been litigated in two recent Supreme Court cases. Riegel v. Medtronic (2008) was a case involving a medical device (a balloon catheter used in heart surgery) that was used in a way inconsistent with the label (directions) and that ruptured and caused an injury. The injured party sued in state court. Ultimately the U.S. Supreme Court held that FDA approval preempted state law. However, this finding was based on an explicit provision in the statute that preempted state court actions for approved medical devices.

Wyeth v. Levine (2009) was a similar case involving a drug rather than a device. Phenergan, an antihistamine used to treat nausea, was improperly administered to Diana Levine, leading to an injury and ultimately to amputation of her arm. She successfully sued the physician and health center where the drug was administered, and then sued the manufacturer (Wyeth) on the grounds that the labeling of the drug (which was approved by the FDA) was inadequate. In this case, the Supreme Court held that there was no preemption- that is, the Court held that the lawsuit under state law could proceed. The difference was that Congress had not specifically preempted state litigation when the FDA approves a drug (unlike the case of a device, where there was explicit preemption.)

While the Court decided these cases on legal grounds, the economics and the health effects are the same in both cases. Indeed, the case for preemption may be stronger for drugs in Wyeth than for devices in Riegel because the approval process for drugs is more stringent than the process for devices. The main point is that both the tort laws and the regulatory process are excessively restrictive, in that both lead to net harm for patients. Piling one overly restrictive process on top of another simply increases harm.

Drugs will be more expensive because of the cost of the tort system. There will be fewer drugs because it will not pay manufacturers to invest in developing as many drugs. Those that are developed and approved will be used less frequently because they will be more expensive. There is no reliable statistical evidence that either the FDA process or the tort system leads to greater safety and much evidence that both lead to increased harm. There is also evidence that newer drugs lead to reduced costs and improved health (Lichtenberg 2003, Lichtenberg and Virabhak 2007). Thus, not allowing preemption will 


\section{Cato Journal}

be a net harm for consumers. Congress could fix this by amending the Food, Drug and Cosmetic Act to allow the same preemption that is now granted to manufacturers of medical devices.

\section{Conclusion}

The three major forces for safety are markets, regulation, and tort law. Markets are the most important source of safety, but the workings of the market in improving safety are not obvious to consumers. This situation creates pressure for tort law and regulation, which often follow some crisis or disaster.

Markets may not provide the optimal amount of safety because of third-party effects and perhaps information deficiencies. In principle, these problems could be corrected by other forces. Classic tort law solves many externality problems (for example, in the case of automobile accidents). Regulation may be able to solve information problems-for example, in cases where risks are difficult to measure or where there are long lags between use of a product and harm. However, both of these systems overreach. Product liability and medical malpractice do not appear to improve safety, and are quite expensive to operate. Regulation often causes harm by delaying new safety enhancing products (particularly drugs). Ambiguous goods that reduce some harms but cause others are the most difficult class of goods.

An important issue is the relationship between regulation and tort law. For medical devices FDA regulation does lead to an exemption from state tort law, but this is not true for drugs. A simple improvement would be to extend this exemption to drugs.

\section{References}

Bureau of Economic Analysis (2010) Current Dollar and Real GDP. Available at www.bea.gov/national.

Calfee, J. E. (1997) "The Ghost of Cigarette Advertising Past." Regulation 20 (3): 35-45.

Calfee, J. E.; Berndt, E. R.; Hahn, R.; Philipson, T.; Rubin, P. H.; and Viscusi, W. K. (2008) "Supreme Court Amicus Brief Regarding Wyeth v. Diana Levine." Available at http://ssrn.com/ abstract $=1142997$.

Durisek, N. J., and Granat, K. J. (2008) "Industry Implementation of Automotive Electronic Stability Control (ESC) Systems, Society 
of Automotive Engineers." Presented at SAE World Congress and Exhibition. Available at http://papers.sae.org/2008-01-0593.

Keeton, R., and O'Connell, J. (1965) Basic Protection for the Traffic Accident Victim: A Blueprint for Reforming Automobile Insurance. Boston: Little Brown.

Landes, W. M., and Posner, R. A. (1987) The Economic Structure of Tort Law. Cambridge, Mass.: Harvard University Press.

Lichtenberg, F. R. (2003) "Pharmaceutical Innovation, Mortality Reduction, and Economic Growth.” In K. Murphy and R. Topel (eds.) Measuring the Gains from Medical Research: An Economic Approach. Chicago: University of Chicago Press.

Lichtenberg, F. R., and Virabhak, S. (2007) "PharmaceuticalEmbodied Technical Progress, Longevity, and Quality of Life: Drugs as 'Equipment for your Health." Managerial and Decision Economics 28 (4-5): 371-92.

Meadows, M. (2006) "Promoting Safe and Effective Drugs for 100 Years." FDA Consumer Magazine. Available at www.fda.gov/ AboutFDA/WhatWeDo/History/ProductRegulation/Promoting SafeandEffectiveDrugsfor100Years/default.htm.

National Bureau of Economic Research (2009) Vital Statistics NCHS's Multiple Cause of Death Data, 1959-2004. Available at www.nber.org/data/multicause.html.

National Highway Traffic Safety Administration (2007) "Federal Motor Vehicle Safety Standards; Electronic Stability Control Systems; Controls and Displays, 49 CFR Parts 571 and 585." Available at http://edocket.access.gpo.gov/2007/ E7-11965.htm.

Peck, J., and Sage, N. (2003) History of GFCI Requirements, 1971-2002, from National Electric Code. Available at www.mikeholt.com/documents/nec/pdf/GFCI_requirement_ page2.pdf.

Peltzman, S. (1973) "An Evaluation of Consumer Protection Legislation: The 1962 Drug Amendments.” Journal of Political Economy 81 (5): 1049-91.

(1975) "The Effects of Automobile Safety Regulation." Journal of Political Economy 83 (4): 677-725.

Polinsky, A. M., and Shavell, S. (2010) “The Uneasy Case for Product Liability." Harvard Law Review 123 (6): 1437-93.

Ribstein, L. (2003) "Bubble Laws." Houston Law Review 40 (77): 79-97. 


\section{Cato Journal}

Riegel v. Medtronic, Inc. (2008) 128 S.Ct. 999.

Rubin, P. H. (1993) Tort Reform by Contract. Washington: AEI Press. 27 (4): 34-37. (2005) “The FDA's Antibiotic Resistance." Regulation (2009) "Scrap the Consumer Product Safety Improvement Act-III.” Forbes.com (27 January).

Rubin, P. H.; Jarrell, G.; and Murphy, R. D. (1988) "Risky Products, Risky Stocks." Regulation 12 (1): 35-39.

Rubin, P. H., and Prince, D. (2002) "The Effects of Product Liability Litigation on the Value of Firms." American Law and Economics Review 4 (1): 44-87.

Rubin, P. H., and Shepherd, J. (2007) "Tort Reform and Accidental Deaths." Journal of Law and Economics 50 (2): 221-38.

Rubin, P. H.; Calfee, J. E.; and Grady, M. F. (1997) "BMW v. Gore: Mitigating The Punitive Economics of Punitive Damages." Supreme Court Economic Review 5: 179-216.

Shavell, S. (1987) Economic Analysis of Accident Law. Cambridge, Mass: Harvard University Press.

Trottman, M. (2008) "Vendors Urge Relaxed Lead-Safety Rule." Wall Street Journal (18 November).

U.S. Census Bureau (2000) Historical National Population Estimates. Available at www.census.gov/popest/archives/1990s.

(2009) Datasets. Available at www.census.gov/popest/ national/national.html.

United Nations Statistics Division (2009) Per Capita GDP at Current Prices, U.S. Dollars. Available from http://data.un.org/Data.aspx?q $=$ GDP\&d=SNAAMA\&f=grID:101; currID:USD;pcFlag: 1 .

Viscusi, W. K., and Aldy, J. E. (2003) "The Value of A Statistical Life: A Critical Review of Market Estimates throughout the World." Journal of Risk and Uncertainty 27 (1): 5-76.

World Health Organization (2004) Data and Statistics. Available at www.who.int/research/en.

Wyeth v. Levine (2009) 555 U.S. 555. 